\title{
COMBINATION OF GAMBIER EXTRACT AND BENZOIC ACID AS INHIBITOR OF CALCIUM SULFATE SCALE FORMATION
}

\author{
Suharso $^{1, \bowtie}$, M. Padli ${ }^{1}$, Tugiyono ${ }^{2}$ and Buhani ${ }^{1}$ \\ ${ }^{1}$ Department of Chemistry, Faculty of Mathematic and Natural Sciences/University of Lampung, \\ J1. Soemantri Brojonegoro No. 1 Bandar Lampung-35145, (Lampung) Indonesia \\ ${ }^{2}$ Department of Biology, Faculty of Mathematic and Natural Sciences/University of Lampung, \\ J1. Soemantri Brojonegoro No. 1 Bandar Lampung-35145, (Lampung) Indonesia \\ ${ }^{凶}$ Corresponding Author: suharso_s@yahoo.com
}

\begin{abstract}
In this study, it was carried out the addition of a mixture of gambier (Uncaria gambir Roxb.) extract and benzoic acid as an inhibitor of scale growth of calcium sulfate using the seeded experiment technique. The experiment was performed on variations in the concentration of calcium sulfate growth solution with variation from 0.15 to $0.25 \mathrm{M}$ by the presence of inhibitor mixture $0-125 \mathrm{ppm}$ and a temperature of $90^{\circ} \mathrm{C}$. Observations on the growth of calcium sulfate crystals formed were carried out by weighing crystals obtained in each series of experiments. Characterization of calcium sulfate crystals obtained was done by particle size analyzer/PSA and scanning electron microscope/SEM. The results obtained showed that the addition of a mixture of gambier extract and benzoic acid at a ratio of 1: 1 may block the formation of calcium sulfate crystals with effectiveness in the range of $2-54 \%$ depending on the concentration of the inhibitor added. The results obtained are supported by data obtained by SEM and PSA analysis. The data obtained from SEM and PSA confirmed that the size of calcium sulfate crystals after the addition of the inhibitor becomes to be smaller than the normal growth.

Keywords: Scaling Inhibitor, Calcium Sulfate, Gambier Extract, Benzoic Acid, Green Inhibitor.

RASĀYAN J. Chem., Vol. 14, No.1, 2021
\end{abstract}

\section{INTRODUCTION}

The use of natural materials to overcome human life problems related to environmental problems has recently been a concern of researchers. ${ }^{1-10}$ The use of natural materials such as plant extracts, algal biomass, fungi, activated carbon, and cassava peel have been carried out by researchers as a corrosion inhibitor and an adsorbent for heavy metals and dyes that pollute the environment. ${ }^{11-35}$ Extract of gambier and kemenyan were also used as inhibitors of inorganic material scale formation. ${ }^{36,37}$ The use of natural materials aims to overcome problems in the industrial world without having to cause new problems for the environment. Gambier (Uncaria gambir Roxb.) extract and modified gambier extract are known as natural materials that promise to inhibit the growth of calcium carbonate $\left(\mathrm{CaCO}_{3}\right)$ and calcium sulfate $\left(\mathrm{CaSO}_{4}\right)$ scale. $^{36-38}$ Modification of gambier extract with several types of organic acids was reported to be able to block the $\mathrm{CaCO}_{3}$ crystal growth. ${ }^{39}$ However, the use of gambier extract modified with benzoic acid as an inhibitor for the growth of $\mathrm{CaSO}_{4}$ crystals is still unknown. Modification of gambier extract in the presence of organic acids such as citric acid or benzoic acid was conducted to control the gambier extract quality. ${ }^{39}$

Noting the potency of the gambier extract modified as an effective inhibitor of $\mathrm{CaCO}_{3}$ scale growth, in this study it was reported that the use of gambier (Uncaria gambir Roxb.) extract modified with benzoic acid as an inhibitor of $\mathrm{CaSO}_{4}$ scale growth. The addition of benzoic acid was carried out to overcome the damage of gambier extract from microorganisms so that it can be stored for a long time. The experiments were conducted using the seeded experiment method by measuring alteration in the weight of $\mathrm{CaSO}_{4}$ crystals produced either without inhibitors or by adding inhibitors. The obtained crystal identification was formed with a particle size analyzer (PSA) and scanning electron microscope (SEM) to prove that inhibitors work in blocking the $\mathrm{CaSO}_{4}$ crystal growth. 


\section{Materials and Instruments}

\section{EXPERIMENTAL}

The instruments used in this study consisted of water baths, plastic bottles, magnetic stirrers, analytic balance (Airshwoth AA-160), Scanning electron microscopy (JEOL jsm-6510, Japan), particle size analyzer (Coulter LS 100Q, United State of America).

The materials used in this study included acetone, benzoic acid, anhydrous calcium chloride, sodium sulfate, aquabidest, acetone, distilled water, filter paper, gambier (Uncaria gambir Roxb.) extract obtained from Padang-West Sumatera and Palembang (South Sumatera) gambier plants. The chemicals were bought from Merck-Germany.

\section{Gambier Extract Preparation}

Extraction of gambier was prepared by smoothing gambier solids (Padang and Palembang). An amount of 100 grams of gambier in the form of powder was placed in $1 \mathrm{~L}$ of distilled water. The gambier solution is heated at $80^{\circ} \mathrm{C}$ and stirred using a stirrer for 2-3 hours. The solution was filtered to obtain a concentration of gambier extract in $100000 \mathrm{ppm}$. This method was repeated in the preparation of $100000 \mathrm{ppm}$ benzoic acid solution. The two solutions were filtered and mixed with a ratio of $1: 1$.

\section{Seed Crystals Production}

Seed crystals were made by blending $1 \mathrm{M}$ anhydrous $\mathrm{CaCl}_{2}$ solution and $1 \mathrm{M} \mathrm{Na}_{2} \mathrm{SO}_{4}$ solution in $50 \mathrm{~mL}$ aquabidest respectively. These compounds were heated and stirred with a magnetic stirrer at $80{ }^{\circ} \mathrm{C}$ for 30 minutes. The mixture was left at room temperature to get seed crystals. The obtained crystals were filtered and washed with cold aquabidest and acetone, continued with drying in an oven at a temperature of $105^{\circ} \mathrm{C}$. This technique was replicated at certain times until a sufficient number of seed crystals were obtained to carry out the experiments.

\section{Inhibitor Activity Test \\ Determination of the Growth of $\mathrm{CaSO}_{4}$ by Variations in Growth Media Concentration without the Presence of Inhibitor}

The growth solutions were produced from blending of $0.15 \mathrm{M} \mathrm{CaCl}_{2}(200 \mathrm{~mL})$ and $\mathrm{Na}_{2} \mathrm{SO}_{4}(200 \mathrm{~mL})$ into a $500 \mathrm{~mL}$ plastic bottle. The mixture was stirred for 15 minutes at $90^{\circ} \mathrm{C}$ and then placed into the water bath for 15 minutes at $90{ }^{\circ} \mathrm{C}$ to reach equilibrium. Then the mixture was poured into 7 plastic bottles contained in the water bath at $90{ }^{\circ} \mathrm{C}$ each with $50 \mathrm{~mL}$ followed by the addition of $200 \mathrm{mg} \mathrm{CaSO}$ crystal seeds into plastic bottles at the same time. Every 5 minutes, the precipitate formed in the bottle is removed, filtered with filter paper, and washed with acetone and then dried at $105 \mathrm{C}$ in the oven. The crystals formed were weighed and they were characterized by SEM and PSA. This experiment was repeated in a variation of the $\mathrm{CaSO}_{4}$ growth media concentration of $0.20-0.25 \mathrm{M}$.

\section{Determination of $\mathrm{CaSO}_{4}$ Crystal Growth by Variations in Growth Media Concentration with the Addition of Inhibitor}

The procedure performed in this experiment was the same as the procedure for determining the $\mathrm{CaSO}_{4}$ growth rate without the presence of inhibitors. But in this experiment, the addition of inhibitors was carried out simultaneously in a solution of $\mathrm{CaCl}_{2}$ and $\mathrm{Na}_{2} \mathrm{SO}_{4}$ before the two solutions were mixed. The inhibitors used were a mixture of gambier extract and benzoic acid solution with a ratio of 1: 1 . The inhibitor concentration was added $0,25,75$, and $125 \mathrm{ppm}$ in the $\mathrm{CaSO}_{4}$ growth media concentration of $0.15,0.20$, and $0.25 \mathrm{M}$. An amount of $\mathrm{CaSO}_{4}$ crystal seeds added was made to remain as much as $200 \mathrm{mg}$. The precipitate formed by the addition of inhibitors was weighed then analyzed by SEM and PSA. The data obtained in the form of the amount of precipitate to time with variations in the concentration of growth solutions and inhibitors, each was plotted as the weight of deposit to time by Microsoft Excel 2013. The slope value obtained from each graph is the $\mathrm{CaSO}_{4}$ scale growth rate. Changes in crystal size or changes in $\mathrm{CaSO}_{4}$ crystal morphology before and after the addition of inhibitors were analyzed by SEM. While changes in the crystal size distribution of $\mathrm{CaSO}_{4}$ before and after the addition of inhibitors were analyzed by PSA.

\section{RESULTS AND DISCUSSION}

Gambier extract is very susceptible to microorganisms and fungi. The quality of gambier extract at room temperature does not last more than 3 days. The addition of benzoic acid to gambier extract with a ratio of 
RASĀYAN J. Chem.

Vol. 14 | No. 1 |141-148| January - March | 2021

1: 1 can improve the quality of mixed extract. This can be proven from the observation that the addition of benzoic acid increases the quality of the mixture. It can last for more than 2 months. The mixture of gambier extract and benzoic acid was then used as an inhibitor to block the $\mathrm{CaSO}_{4}$ crystals growth. The graph of changes in the weight of $\mathrm{CaSO}_{4}$ crystal precipitate to time in various variations of $\mathrm{CaSO}_{4}$ growth solution concentration is shown in Fig.-1. The growth solution of $\mathrm{CaSO}_{4}$ was made in the concentration range of 0.15 to $0.25 \mathrm{M}$. In this concentration range it is possible to observe the growth of $\mathrm{CaSO}_{4}$ crystals and measure the weight gain of the crystals produced. From the data in Fig.-1 it can be observed that the growth of $\mathrm{CaSO}_{4}$ crystals at higher concentrations takes place faster. In this case, the growth of $\mathrm{CaSO}_{4}$ crystals at a $0.25 \mathrm{M}$ growth media takes place faster than the growth media concentration by 0.20 and $0.15 \mathrm{M}$ as indicated in Fig.-1. The fast growth rate of $\mathrm{CaSO}_{4}$ crystals is evidenced by the increase in the amount of $\mathrm{CaSO}_{4}$ crystals formed. The amount of $\mathrm{CaSO}_{4}$ crystals formed in the final state of observation in the volume of $1 \mathrm{~L}$ solution with the growth media concentration of $0.25 \mathrm{M}$ approached $14 \mathrm{~g}$. While the amount of crystals formed at the growth media concentrations of 0.20 and $0.15 \mathrm{M}$ are in the range of 11 and $7 \mathrm{~g}$. In general, the increase in the amount of deposits formed from the material inorganic is immediately comparable to the rise in the concentration of the growth solution of the material. This is in line with some of the experiment results from previous works as reported by researchers on calcium phosphate material ${ }^{40}$ and on calcium carbonate and sulfate materials. ${ }^{41,42}$

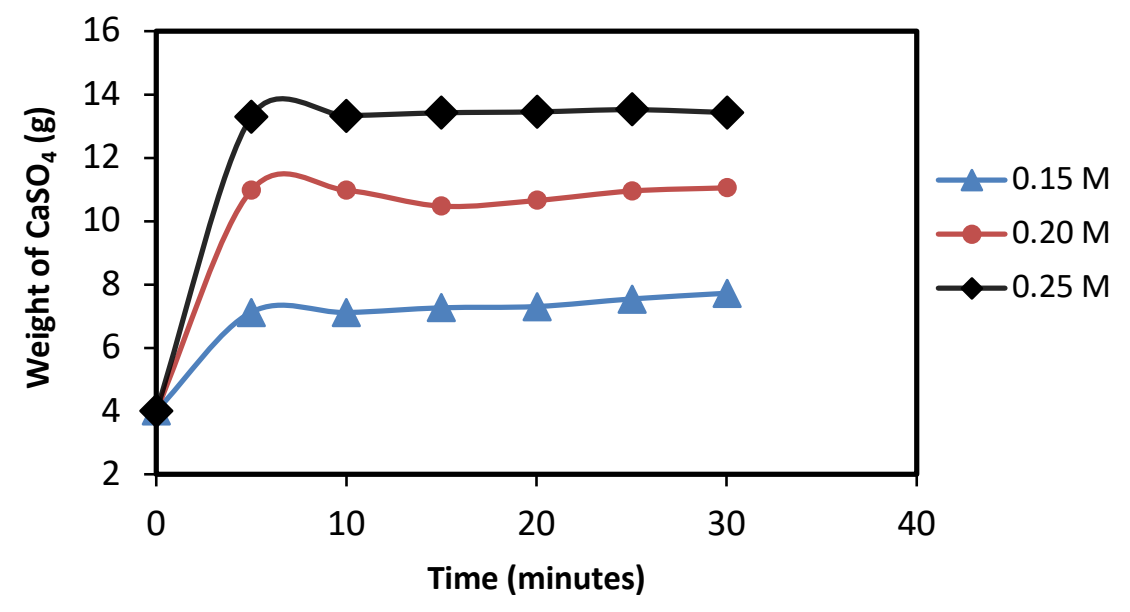

Fig.-1: Weight Changes of $\mathrm{CaSO}_{4}$ Crystals at Different Growth Media Concentrations

The influence of the inhibitor addition from the gambier extract and benzoic acid mixture on a range of $\mathrm{CaSO}_{4}$ growth media concentrations may be identified in Figs.-2, 3, and 4. In these figures it may be observed that the addition of a mixture of gambier extract and benzoic acid can impede the $\mathrm{CaSO}_{4}$ crystal growth. Increasing the amount of mixture of gambier extract and benzoic acid into growth solutions increases the inhibitor's effectiveness in blocking the $\mathrm{CaSO}_{4}$ crystals growth. But when the concentration of the growth solution was made higher, the inhibitor ability decreased in blocking the $\mathrm{CaSO}_{4}$ crystals growth. This is due to the higher the concentration of $\mathrm{CaSO}_{4}$ growth solution $(0.25 \mathrm{M}), \mathrm{CaSO}_{4}$ crystal growth takes place faster than the growth media concentration of 0.15 and $0.20 \mathrm{M}$ which results in reduced inhibitor work. This also occurs in the addition of tobacco extract in blocking the growth of $\mathrm{CaCO}_{3}$ and $\mathrm{CaSO}_{4}$ crystals. $^{43}$

The inhibitors effectiveness in blocking $\mathrm{CaSO}_{4}$ scale formation can be measured by the percent effectiveness of inhibitors and calculated using Eqn.-1.,44

Effectiveness of inhibitors $(\mathrm{EI} \%)=\frac{(W a-W b)}{(W o-W b)} \times 100$

Where, $W_{a}$ is the weight of the precipitate with the addition of inhibitors at equilibrium $(\mathrm{g})$ in volume $1 \mathrm{~L}$, $W_{b}$ is the weight of the precipitate without the addition of inhibitors at equilibrium $(\mathrm{g}), W_{o}=$ initial weight $(\mathrm{g})$ of seed crystals added into the growth media in volume $1 \mathrm{~L}$. 
RASĀYAN J. Chem.

Vol. 14 | No. 1 |141-148| January - March | 2021

The results of the calculation of the inhibitor's effectiveness (\%) in a mixture of gambier extract and benzoic acid in blocking the growth of $\mathrm{CaSO}_{4}$ crystals at inhibitor concentrations $0-125 \mathrm{ppm}$ and concentrations of $\mathrm{CaSO}_{4}$ growth solution by $0.15-0.25 \mathrm{ppm}$ are displayed in Table-1. From Table 1 it can be observed that the ability of the mixture of gambier extract and benzoic acid in blocking the formation of $\mathrm{CaSO}_{4}$ crystals in the range of $2-54 \%$. The highest ability of the mixture of gambier extract and benzoic acid in inhibiting $\mathrm{CaSO}_{4}$ scale formation (54\%) takes place at the $\mathrm{CaSO}_{4}$ concentration $(0.15 \mathrm{M})$ by the volume of inhibitors appended as much as $125 \mathrm{ppm}$. While the lowest ability of the mixture of gambier extract and benzoic acid in blocking the formation of $\mathrm{CaSO}_{4}$ scale $(2 \%)$ takes place at the $\mathrm{CaSO}_{4}$ growth solution concentration by 0.20 and $0.25 \mathrm{M}$ with the amount of inhibitors added as much as $25 \mathrm{ppm}$. The addition of the mixture of gambier extract and benzoic acid solution as much as $125 \mathrm{ppm}$ followed by an increase in the $\mathrm{CaSO}_{4}$ growth solution concentration from 0.15 to $0.25 \mathrm{M}$ resulted in the decreased inhibitory ability of this inhibitor. This is also shown in the addition of kemenyan extract in blocking the formation of calcium carbonate crystals. ${ }^{37}$ A similar case was also found in the presence of poly (citric acid) to the growth of $\mathrm{CaSO}_{4}$ crystals. $^{2}$

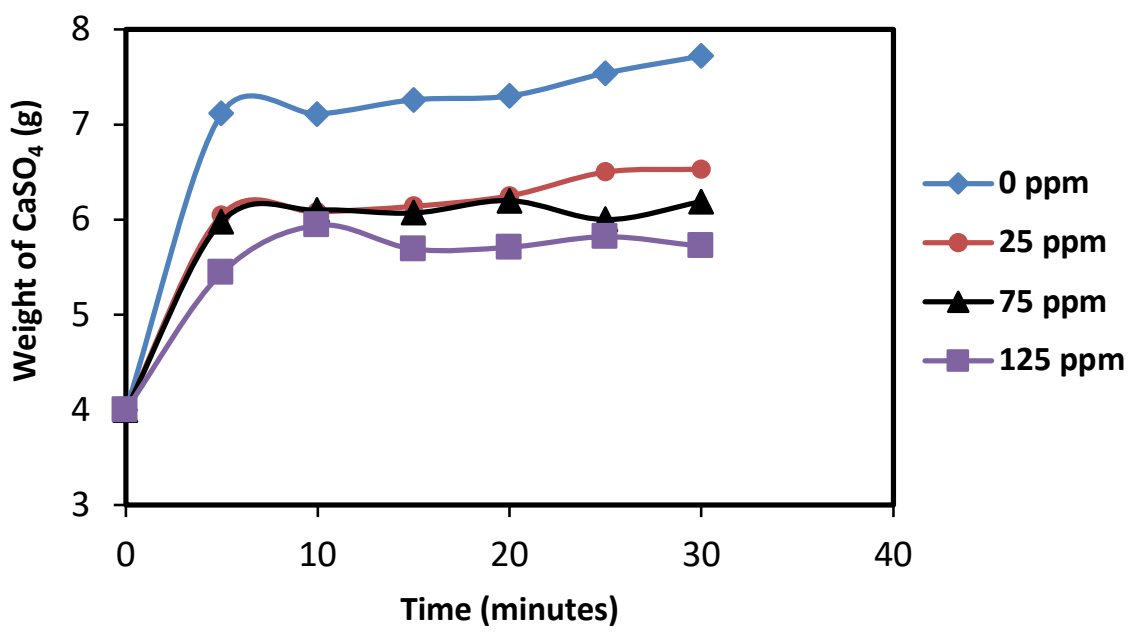

Fig.-2: Changes in $\mathrm{CaSO}_{4}$ Crystal Weight at A Concentration of the $\mathrm{CaSO}_{4}(0.15 \mathrm{M})$ with Variations in the Concentration of Addition of Inhibitors

To prove visually the inhibitor work in blocking the $\mathrm{CaSO}_{4}$ crystals growth, the $\mathrm{CaSO}_{4}$ crystals formed without the addition of inhibitors and with the addition of inhibitors were observed by a scanning electron microscope. The data of the analysis with SEM are described in Fig.-5. In Fig.-5 it may be observed that the morphology of $\mathrm{CaSO}_{4}$ crystals, in general, has not changed. However, the $\mathrm{CaSO}_{4}$ crystal size by the presence of inhibitors makes smaller and more fragile textures.

Deeper observations on the $\mathrm{CaSO}_{4}$ crystal size with and without the appearance of inhibitors were carried out taking a particle size analyzer (PSA). The results of the analysis of $\mathrm{CaSO}_{4}$ crystal size without and with the addition of inhibitors may be referred to in Fig.-6. Figure-6 represents that the presence of inhibitors inside the growth media of $\mathrm{CaSO}_{4}$ changes the particle size distribution of $\mathrm{CaSO}_{4}$ that grows. The shift in the particle size distribution of $\mathrm{CaSO}_{4}$ by the appearance of inhibitors occurred with the lower particle size distribution compared to the addition of inhibitors. The average diameter of $\mathrm{CaSO}_{4}$ particle without the addition of inhibitors is around $20 \mathrm{~m} \mu$ and after the addition of inhibitors, the particle diameter of $\mathrm{CaSO}_{4}$ becomes around $10 \mathrm{~m} \mu$ (Fig.-6).

The existence of gambier extract and benzoic acid solutions containing chemical compounds such as tannins, catechins, quercetin, and benzoic acid serve as inhibitors to block the $\mathrm{CaSO}_{4}$ scale growth. ${ }^{36,37}$ The mechanism of inhibitor inhibition in blocking the growth of the $\mathrm{CaSO}_{4}$ scale in the case of this study can be through the threshold inhibition mechanism. In the threshold inhibition mechanism, the solubility of $\mathrm{CaSO}_{4}$ due to the presence of compounds contained in gambier and benzoic acid can increase the solubility of $\mathrm{CaSO}_{4}$ so that the supersaturation as a condition for crystallization to be reduced. The mechanism of complex formation between $\mathrm{Ca}^{2+}$ metal ions and functional groups found in chemical compounds contained 
RASĀYAN J. Chem.

Vol. 14 | No. 1 |141-148| January - March | 2021

in gambier and benzoic acid such as carboxylates can also occur. The complex formation between the $\mathrm{Ca}^{2+}$ metal ions and carboxylic groups inhibits the formation of a reaction between ions of $\mathrm{Ca}^{2+}$ and $\mathrm{SO}_{4}{ }^{2-}$ so that the growth or formation of $\mathrm{CaSO}_{4}$ crystals becomes slowed.

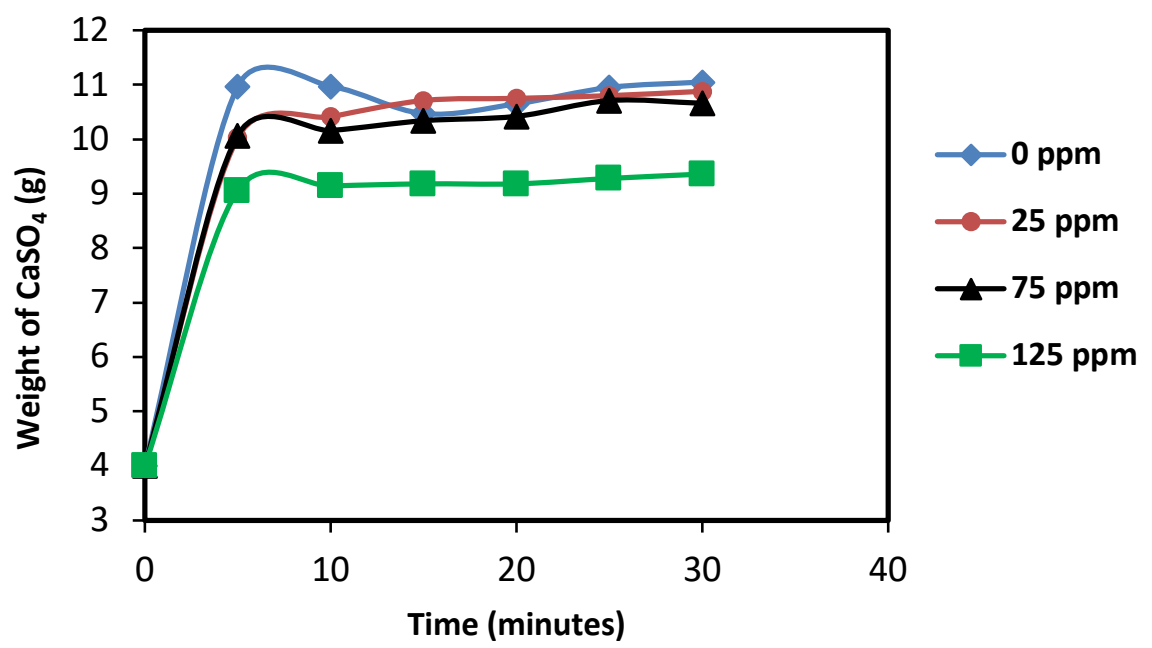

Fig.-3: Changes in $\mathrm{CaSO}_{4}$ Crystal Weight at A Concentration of $\mathrm{CaSO}_{4}(0.20 \mathrm{M})$ by Variations in the Concentration of Inhibitor Addition

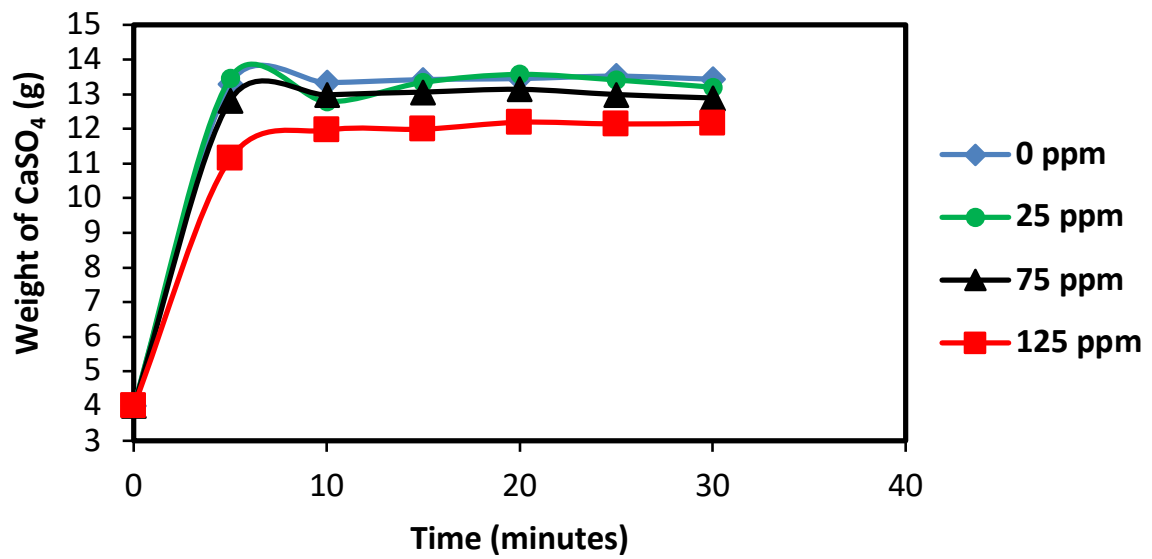

Fig.-4: Changes in $\mathrm{CaSO}_{4}$ Crystal Weight at A Concentration of $\mathrm{CaSO}_{4}(0.25 \mathrm{M})$ with Variations in the Concentration of Inhibitor Addition

Table-1: Effectiveness of Inhibitors with the Growth Solution Concentration Range

\begin{tabular}{c|c|c|c|c|c}
\hline \multicolumn{6}{c}{ Concentrations of $\mathrm{CaSO}_{4}$ Growth Solution } \\
\hline \multicolumn{2}{c|}{$0.15(\mathrm{M})$} & \multicolumn{2}{c}{$0.20(\mathrm{M})$} & \multicolumn{2}{c}{$0.25(\mathrm{M})$} \\
\hline $\begin{array}{c}\text { Inhibitor } \\
\begin{array}{c}\text { Inhibitor } \\
(\mathrm{ppm})\end{array}\end{array}$ & $\begin{array}{c}\text { Inhibitor } \\
\text { Effectiveness } \\
(\%)\end{array}$ & $\begin{array}{c}\text { Concentration } \\
(\mathrm{ppm})\end{array}$ & $\begin{array}{c}\text { Inhitor } \\
\text { Effectiveness } \\
(\%)\end{array}$ & $\begin{array}{c}\text { Inhibitor } \\
\text { Concentration } \\
(\mathrm{ppm})\end{array}$ & $\begin{array}{c}\text { Inhibitor } \\
\text { Effectiveness } \\
(\%)\end{array}$ \\
\hline 0 & 0.00 & 0 & 0.00 & 0 & 0.00 \\
25 & 31.99 & 25 & 2.41 & 25 & 2.43 \\
75 & 41.13 & 75 & 5.53 & 75 & 5.73 \\
125 & 53.76 & 125 & 23.97 & 125 & 13.47 \\
\hline
\end{tabular}

The presence of tannins in gambier also has a contribution to the crystal dispersion mechanism. The tannin compound which is a macromolecular compound can absorb the surface of $\mathrm{CaSO}_{4}$ crystals derived from crystalline seeds added to the growth solution as a result of $\mathrm{CaSO}_{4}$ crystals being dispersed in small sizes as shown in Fig. 6. The mechanism of dispersion and the formation of complexes on the growth of $\mathrm{CaSO}_{4}$ 
RASĀYAN J. Chem.

Vol. 14 | No. 1 |141-148| January - March | 2021

crystals was also common also of poly (citric acid) which can inhibit the growth of $\mathrm{CaSO}_{4}$ crystals with inhibitory effectiveness exceeding $90 \%{ }^{2}$ The mechanism of dispersion also occurred in blocking the formation of calcium phosphate crystal by the presence of poly (acrylic acid). ${ }^{45}$ The results of this work are in line with the inhibition of growth of $\mathrm{CaSO}_{4}$ crystals in the addition of mixed phosphonate inhibitors ${ }^{46}$ and modified gambier with kemenyan. ${ }^{47}$ The results of this work also may be contrasted with another inhibitor as liquid smoke to block the growth rate of calcium carbonate. ${ }^{48}$ Thus it can be stated that the addition of a mixture of gambier extracts and benzoic acid by a comparison of $1: 1$ to the growth solution of $\mathrm{CaSO}_{4}$ can inhibit the growth of $\mathrm{CaSO}_{4}$ scale.

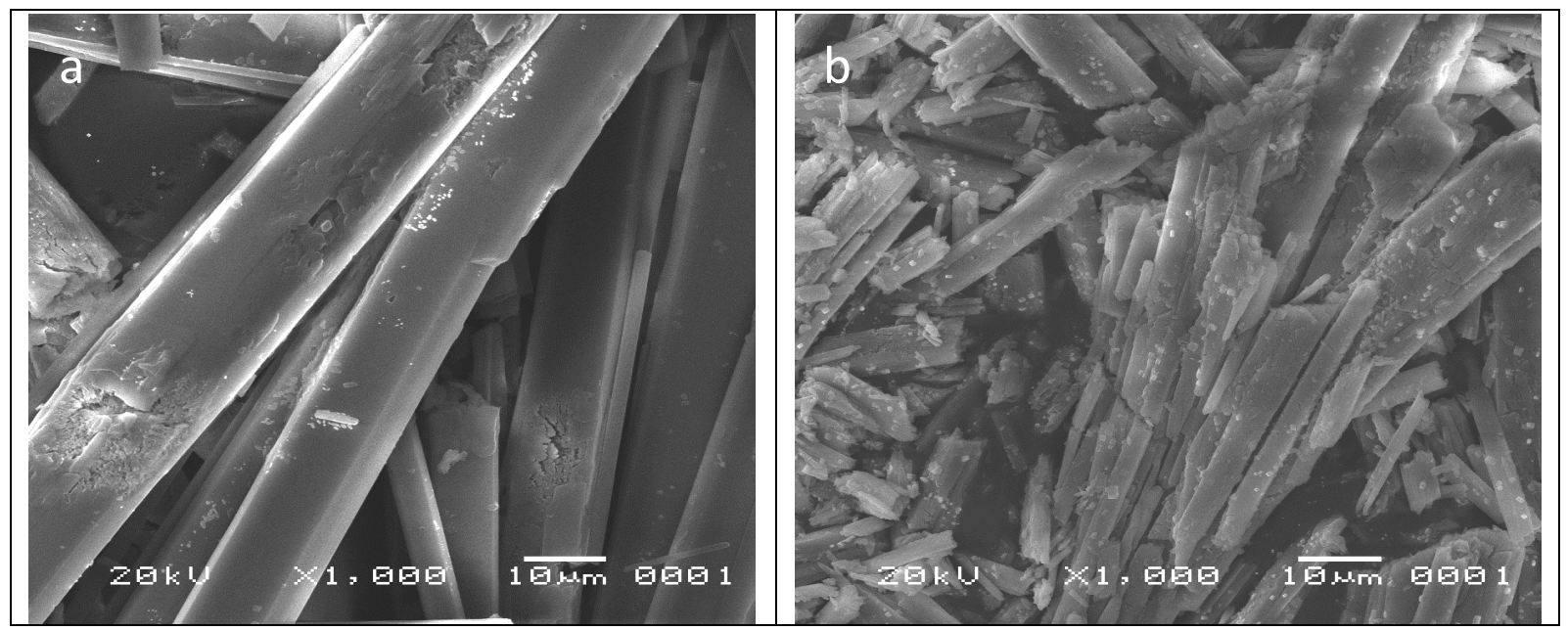

Fig -5: Morphology of $\mathrm{CaSO}_{4}$ Crystals (a) without and (b) with the Addition of Inhibitors

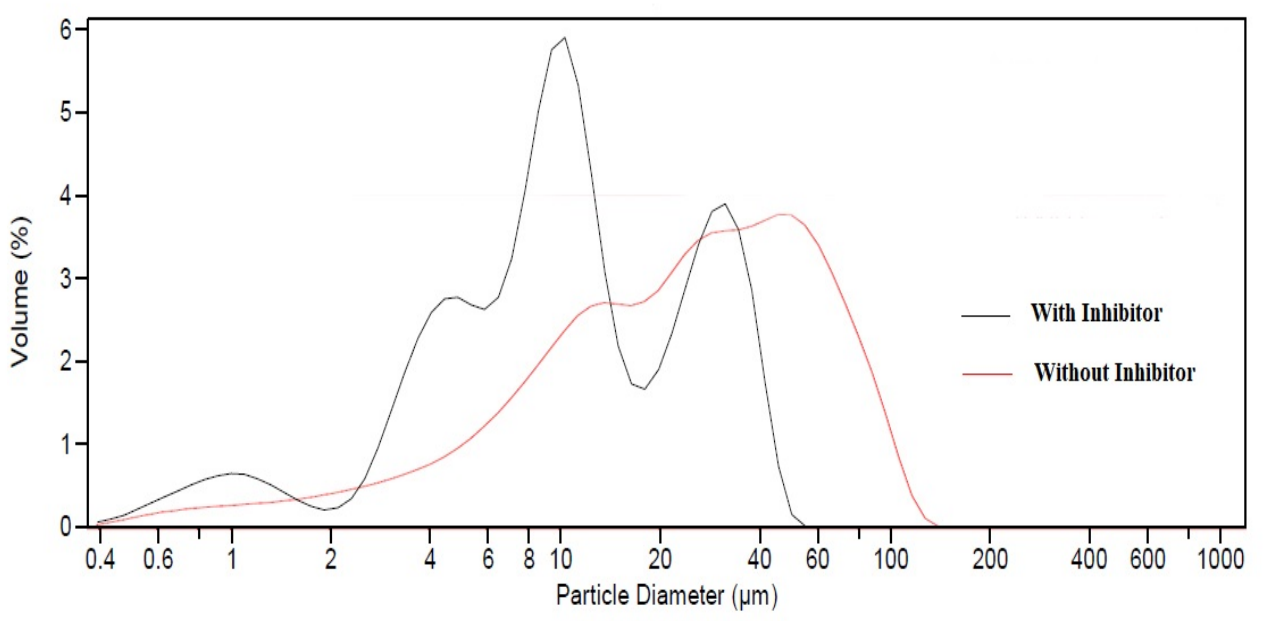

Fig.-6: Diameter of $\mathrm{CaSO}_{4}$ Crystal Particles without and with the Addition of Inhibitors

CONCLUSION

The addition of inhibitor mixture extract gambier and benzoic acid at a ratio of $1: 1$ can block the $\mathrm{CaSO}_{4}$ crystals growth with the effectiveness of the inhibitor of $2-54 \%$ in the concentration of $\mathrm{CaSO}_{4}$ growth media by $0.15-0.25 \mathrm{M}$. The effectiveness of inhibitors depends on the $\mathrm{CaSO}_{4}$ growth media concentration and added inhibitor. The inhibitor effectiveness was $54 \%$ in the $\mathrm{CaSO}_{4}$ growth solution concentration of $0.15 \mathrm{M}$ by the addition of $125 \mathrm{ppm}$ inhibitor. The effectiveness of inhibitors will decrease when the growth media concentration is increased from $0.15 \mathrm{M}$ and the added inhibitor concentration is lower than $125 \mathrm{ppm}$. The data of the characterization by SEM and PSA confirmed that the morphology and diameter size of $\mathrm{CaSO}_{4}$ crystals were smaller with the inhibitor addition of gambier extract and benzoic acid mixture. 
RASĀYAN J. Chem.

Vol. 14 | No. 1 |141-148| January - March | 2021

\section{ACKNOWLEDGMENT}

We are thankful to the Ministry of Research and Technology/Institute of Research and National Innovation of the Republic of Indonesia (Kemenristek/Brin), Ministry of Education and Culture of Republic of Indonesia (Kemendikbud), and Research and Community Service Institute of the University of Lampung (LPPM Universitas Lampung) for the support this project.

\section{REFERENCES}

1. M.K. Nayunigari, A. Maity, S. Agarwal, V.K. Gupta, Journal of Molecular Liquids, 214, 400(2016), DOI:10.1016/j.molliq.2015.11.034

2. Y. Zhao, L. Jia, K. Liu, P. Gao, H. Ge, L. Fu, Desalination, 2016, 392, 1(2016), DOI: 10.1016/j.desal.2016.04.010

3. L. Yang, W. Yang, B. Xu, X. Yin, Y. Chen, Y. Liu, Y. Ji, Y. Huan, Desalination, 416, 166 (2017), DOI: 10.1016/j.desal.2017.05.010

4. N. Karaman, W. Mangestiyono, S. Muryanto, J. Jamari, A. P. Bayuseno, Rasayan Journal of Chemistry, 12, 1734 (2019), DOI:10.31788/RJC.2019.1245380

5. R. Thilagavathi, A. Prithiba, R. Rajalakshmi, Rasayan Journal of Chemistry, 12, 431(2019), DOI: 10.31788/RJC.2019.1225133

6. W. Mangestiyono, S. Muryanto, J. Jamari and A.P. Bayuseno, Rasayan Journal of Chemistry, 12, 192 (2019), DOI:10.31788/RJC.2019.1215055

7. G. Liu, M. Xue, H. Yang, Desalination, 419, 133(2017), DOI:10.1016/j.desal.2017.06.017

8. R. Menzri, S. Ghizellaoui, M. Tlili, Desalination, 404, 147 (2017), DOI:10.1016/j.desal.2016.11.005

9. X. Qiang, Z. Sheng, H. Zhang, Desalination, 309, 237(2013), DOI:10.1016/j.desal.2012.10.025

10. H. Zhang, X. Luo, X. Lin, P. Tang, X. Lu, M. Yang, Y. Tang, Desalination, 381, 1(2016), DOI: 10.1016/j.desal.2015.11.029

11. V.I. Vorobyova, M.I. Skiba, A.S. Shakun, S.V. Nahirniak, International Journal of Corrosion and Scale Inhibition, 8, 150(2019), DOI:10.17675/2305-6894-2019-8-2-1

12. A. Boukhraz, A. Chaouik, R. Salghi, H. Elhartiti, N. Saouide el ayne, A. Zaher, M. Ouhssine, International Journal of Corrosion and Scale Inhibition, 8, 291(2019), DOI:10.17675/2305-68942019-8-2-11

13. Buhani, F. Hariyanti, Suharso, Rinawati, Sumadi, Desalination and Water Treatment, 142, 331(2019), DOI: 10.5004/dwt.2019.23533

14. Buhani, Suharso, L. Aprilia, Indonesian Journal of Chemistry, 12, 94 (2012).

15. Buhani, Rinawati, Suharso, D. P. Yuliasari, S.D. Yuwono, Desalination and Water Treatment, 80, 203 (2017), DOI: 10.5004/dwt.2017.20932

16. Y.G. Bermüdez, I.L.R. Rico, O.G. Bermüdez, E. Guibal, Chemical Engineering Journal, 166, 122 (2011), DOI:10.1016/j.cej.2010.10.038

17. S. Zakhama, H. Dhaouadi, F.M. Henni, Bioresource Technology, 102, 786(2011), DOI: 10.1016/j.biortech.2010.08.107

18. K. Vijayaraghavan, M. Sathishkumar, R. Balasubramanian, Desalination, 265, 54(2011), DOI: 10.1016/j.desal.2010.07.030

19. D. Bulgariu, L. Bulgariu, Bioresource Technology, 103, 489 (2012), DOI: 10.1016/j.biortech.2011.10.016

20. Y. Xiong, J. Xu, W. Shan, Z. Lou, D. Fang, S. Zang, G. Han, Bioresource Technology, 127, 464 (2013), DOI:10.1016/j.biortech.2012.09.099

21. M.M. Areco, S. Hanela, J. Duran, M.S. Afonso, Journal of Hazardous Material, 213-214, 123 (2012), DOI: 10.1016/j.jhazmat.2012.01.073

22. V.K. Gupta, A. Rastogi, Journal of Hazardous Material, 152, 407(2008),DOI: 10.1016/j.jhazmat.2007.07.028

23. W.O. Wan Maznah, A.T. Al-Fawwaz, M. Surif, Journal of Environmental Sciences, 24, 1386 (2012), DOI: $10.1016 / \mathrm{S} 1001-0742(11) 60931-5$

24. M.M. Montazer-Rahmati, P. Rabbani, A. Abdolali, A.R. Keshtkar, Journal of Hazardous Material, 185, 401(2011), DOI:10.1016/j.jhazmat.2010.09.047

25. M. Mukhopadhyay, S.B. Noronha, G.K. Suraishkumar, Bioresource Technology, 98, 1781 (2007), GAMBIER EXTRACT AND BENZOIC ACID AS INHIBITORS 147

Suharso et al. 
RASĀYAN J. Chem.

Vol. 14 | No. 1 |141-148| January - March | 2021

DOI:10.1016/j.biortech.2006.06.025

26. Q. Peng, Y. Liu, G. Zeng, W. Xu, C. Yang, J. Zhang, Journal of Hazardous Material, 177, 676 (2010), DOI:10.1016/j.jhazmat.2009.12.084

27. C. Gok, D. Turkozu, S. Aytas, Journal of Radioanalytical and Nuclear Chemistry, 287, 533(2011), DOI:10.1007/s10967-010-0788-x

28. Buhani, M. Puspitarini, Rahmawaty, Suharso, M. Rilyanti, Sumadi, Oriental Journal of Chemistry, 34, 2043(2018), DOI:10.13005/ojc/3404043

29. V. Ramya, D. Murugan, C. Lajapathirai, P. Saravanan, A. Sivasamy, Journal of Environmental Chemical Engineering, 7, 102798 (2019), DOI:10.1016/j.jece.2018.11.043

30. S. Senthilkumaar, P. Kalaamani, C.V. Subburaam, Journal of Hazardous Material, 136, 800 (2006), DOI:10.1016/j.jhazmat.2006.01.045

31. S. Kaur, S. Rani, R.K. Mahajan, Desalination and Water Treatment, 53, 543(2015).

32. T. Pankaj, P.A. Joy, Nanoscience and Nanotechnology Letters, 1, 171(2009), DOI: 10.1166/nnl.2009.1031

33. T. Calvete, E.C. Lima, N.F. Cardoso, S.L.P. Dias, E.S. Ribeiro, Clean - Soil, Air, Water, 38, 521 (2010), DOI:10.1002/clen.201000027

34. H.K. Jeswani, H. Gujba, N.W. Brown, E.P.L. Roberts, A. Azapagic, Journal of Cleaner Production, 89, 203(2015), DOI:10.1016/j.jclepro.2014.11.017

35. Suharso, Buhani, Asian Journal of Chemistry, 23, 1112 (2011).

36. Suharso, Buhani, S. Bahri, T. Endaryanto, Desalination, 265, 102(2011), DOI:10.1016/j.desal.2010.07.038

37. Suharso, N.A. Sabriani, Tugiyono, Buhani, T. Endaryanto, Desalination and Water Treatment, 92, 38 (2017), DOI:10.5004/dwt.2017.21478

38. Suharso, Buhani, S. Bahri S., T. Endaryanto, Asian Journal of Research in Chemistry, 3, 183 (2010).

39. Suharso, T. Reno, T. Endaryanto, Buhani, Journal of Water Process and Engineering, 18, 1(2017), DOI: 10.1016/j.jwpe.2017.05.004

40. G. Liu, M. Xue, Q. Liu, and Y. Zhou, Clean Technologies and Environmental Policy, 19, 917(2017), DOI: $10.1007 / \mathrm{s} 10098-016-1258-0$

41. G. Liu, M. Xue, Q. Liu, Y. Zhou, and J. Huang, Tenside Surfactants Detergents, 53, 235 (2016).

42. Suharso, Buhani, L. Aprilia, Asian Journal of Chemistry, 26, 6155(2014).

43. H. Wang, M. Gao, Y. Guo, Y. Yang, R. Hu, Desalination, 398, 198(2016), DOI:10.1016/j.desal.2016.07.035

44. S. Patel, M.A. Finan, Desalination, 124, 63(1999), DOI:10.1016/S0011-9164(99)00089-2

45. Z. Amzad, International Journal of Corrosion and Scale Inhibition, 3, 177(2014), DOI:10.17675/2305-6894-2014-3-3-177-189

46. A. Khormali, A.R. Sharifov, D.I. Torba, Journal of Petroleum Science and Engineering, 164, 245(2018), DOI:10.1016/j.petrol.2018.01.055

47. Suharso, Buhani, H.R. Utari, Tugiyono, H. Satria, Desalination and Water Treatment, 169, 22(2019), DOI:10.5004/dwt.2019.24664

48. Suharso, E. Setiososari, A.A. Kiswandono, Buhani, H. Satria, Desalination and Water Treatment, 169, 29(2019), DOI:10.5004/dwt.2019.24707

[RJC-5947/2020] 